\title{
The Isolation of Nuclei from the Filamentous Fungus Aspergillus nidulans
}

\author{
By M. A. GEALT, G. SHEIR-NEISS AND N. R. MORRIS \\ Department of Pharmacology, Rutgers Medical School, Piscataway, \\ New Jersey 08854, U.S.A.
}

(Received 4 August 1975; revised 25 November 1975)

SUMMARY

\begin{abstract}
A method has been developed for isolating nuclei from the filamentous fungus Aspergillus nidulans. In this procedure, the mycelia from $\mathrm{I} 4$ to $16 \mathrm{~h}$ spore-derived cultures of $A$. nidulans NRI, a stable diploid strain, were frozen with liquid nitrogen and homogenized in a Waring blender. After homogenization, the mycelia were warmed to $4{ }^{\circ} \mathrm{C}$ and the nuclei were purified from the homogenate by differential centrifugation followed by sedimentation through $2 \cdot \mathrm{I}$ M-sucrose. The final nuclear yield was 15 to $20 \%$, based on DNA estimations. The purified nuclear pellet was free of whole cells. The morphology of the isolated nuclei resembled that of the in situ nuclei; they contained a nucleolus, chromatin, and had a surrounding double membrane. The purified nuclei were characterized by a DNA:RNA: protein ratio of $1: 2 \cdot 8: 8 \cdot 7$.
\end{abstract}

\section{INTRODUCTION}

It is difficult to isolate and purify the nuclei of filamentous fungi in the amounts necessary for biochemical analysis. The major problem encountered is to disrupt the tough cell wall without simultaneously destroying the fragile nucleus. Enzymic digestion of the cell wall has been used to form protoplasts of Saccharomyces species which can then be lysed to release nuclei (Doi \& Doi, 1974; Rozijn \& Tonino, 1964; Wintersberger, Smith \& Letnansky, 1973). Although protoplast formation using Aspergillus nidulans has been reported (Peberdy \& Gibson, 1971) we have been unable to establish conditions under which it is possible to process sufficient quantities of mycelia to obtain nuclei for biochemical analysis. Physical disruption of the cell wall has been used to isolate nuclei from Saccharomyces cerevisiae (Bhargava \& Halvorson, I97I), Achyla bisexualis (Jaworski \& Horgen, 1973), and Neurospora crassa (Reich \& Tsuda, 1961). Freezing of mycelium in liquid nitrogen before homogenization has been used to isolate $N$. crassa mitochondria (Minssen \& Munkres, 1973) and polyribosomes (Sargent, 1973).

We report here the details of an isolation procedure for $A$. nidulans nuclei based on homogenization in liquid nitrogen. The criteria used for this nuclear purification were: the absence of any intact cells in the final nuclear fraction; the morphological similarity of in situ and isolated nuclei; and the presence of nuclear proteins, e.g. histones. The characterization of histones from the purified nuclei has been reported elsewhere (Felden, Sanders \& Morris, 1976).

\section{METHODS}

Organism. Aspergillus nidulans (Eidam) Wint. strain NRI was used; it is a stable diploid strain which is homozygous for a temperature-sensitive mutation at the bim- 7 locus. At the restrictive temperature, this strain exhibits an increased mitotic index and inhibition of 
nuclear division. The diploid strain was the result of a mating between uvts706, the original bim-7 isolate from FGSCI 54 (Morris, 1976), and a derivative of FGSC99 into which the same bim- 7 conditional mutation had been crossed. The genotype of Uvts706 is ade-2o, bio-I, whi-2, nit-3, slpI2, met-I, nic-2, lac-I, bim-7, cho, cha. The genotype of the bim-7 FGSC99 strain is sup-I ade-20, pro-I, pab-I, ylo, ade-20, Acr-I, nic-2, lac-I, bim-7. The resulting diploid required nicotine, would not utilize lactate, had a leaky adenine requirement, and was more sensitive to acriflavin than the wild type. A diploid strain was used to develop this nuclear isolation procedure because its increased nuclear size and mass aided purification.

Growth. Cultures were grown for 14 to $16 \mathrm{~h}$ at $32^{\circ} \mathrm{C}$ with shaking (200 rev./min) in YG medium $\left[0.5 \%(\mathrm{w} / \mathrm{v})\right.$ yeast extract, $2 \%(\mathrm{w} / \mathrm{v})$ dextrose]. An initial inoculum of $\mathrm{I} \times 10^{6}$ to $5 \times 10^{6}$ conidia/ml in $\mathrm{I} 1$ of medium gave a final yield of approximately Io $\mathrm{g}$ blotted wet weight.

Microscopy. Nuclear isolation was monitored by fluorescence microscopy using a Zeiss Universal microscope with vertical illumination (exciter filters BG-38 and BG-I2, barrier filter 53/44). Acridine orange (C.I. 46005) at a concentration of $50 \mathrm{mg} \mathrm{l}^{-1}$ was used to stain the material; the same concentration was used by Clutterbuck \& Roper (I966). Homogenization buffer was used as the solvent for the stain because its osmotic properties helped preserve the nuclear structure. Before staining, whole cells were fixed in modified Helly solution as described by Robinow \& Caten (1969); but the homogenate and purified fractions were stained without fixing so that nuclear purification could be evaluated without causing any delay in the isolation procedure. With fluorescence microscopy, the nuclei were easily and rapidly distinguished from other cellular components, many of which, after homogenization, were indistinguishable by either light or phase-contrast microscopy.

For electron microscopy, the material was fixed in $\mathrm{I} \cdot 5 \%(\mathrm{w} / \mathrm{v}) p$-formaldehyde and $\mathrm{I} \%$ (v/v) glutaraldehyde in the homogenization buffer, post-fixed with $\mathrm{I} \%(\mathrm{w} / \mathrm{v})$ osmium tetroxide in veronal acetate buffer $(\mathrm{pH} 6 \cdot 2)$, stained with $0.5 \%(\mathrm{w} / \mathrm{v})$ uranyl acetate in the same buffer, and post-stained with lead citrate. Sections were observed at $80 \mathrm{kV}$ with a JEM rooC electron microscope.

Solutions. The homogenization buffer contained: Io mM-PIPES (piperazine- $N, N^{\prime}$-bis-2-

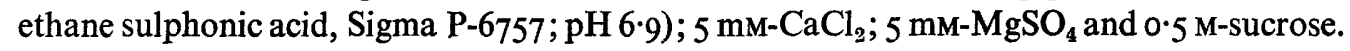
The buffered 2.I M sucrose solution was identical to the homogenization buffer except that $2 \cdot \mathrm{I}$ M-sucrose was substituted for $0.5 \mathrm{M}$-sucrose.

$D N A, R N A$ and protein analysis. All treatments were performed at $4{ }^{\circ} \mathrm{C}$ except where noted. Samples to be analysed were precipitated with perchloric acid (PCA, final concentration $0.25 \mathrm{M}$ ) for $30 \mathrm{~min}$. The precipitate was centrifuged, resuspended in distilled water, and sonicated (Sonifier cell disrupter, Model WI85D, Bronson Power Co., Plainview, N.Y., U.S.A.) using two $15 \mathrm{~s}$ bursts at $55 \mathrm{~W}$ with the micro-tip. The sonicate was washed (Io to $20 \mathrm{vol}$./wash) twice with $0.5 \mathrm{M}$-PCA, once with $95 \%$ ethanol, and once again with $0.5 \mathrm{M}$ PCA. Nucleic acids were extracted twice for 20 min with $3.5 \mathrm{ml}$ of $0.5 \mathrm{M}-\mathrm{PCA}$ at $85^{\circ} \mathrm{C}$. Protein was dissolved in I M-NaOH at $60^{\circ} \mathrm{C}$ for I $\mathrm{h}$.

DNA was determined by the diphenylamine reaction (Giles \& Myers, 1965) and RNA by the orcinol reaction (Schneider, I957). Protein was determined by the method of Lowry et al. (195I).

Isolation of nuclei. The nuclear isolation procedure is outlined in Fig. I. Shake cultures were collected by filtering through Miracloth (Chicopee Mills Inc., New York, U.S.A.; Calbiochem 475855), washed with deionized water at room temperature, blotted dry and weighed. Each $150 \mathrm{~g}$ of blotted mycelium was resuspended in approximately $100 \mathrm{ml}$ of homogenization buffer and mixed to a paste-like consistency. This mixture was then spooned 


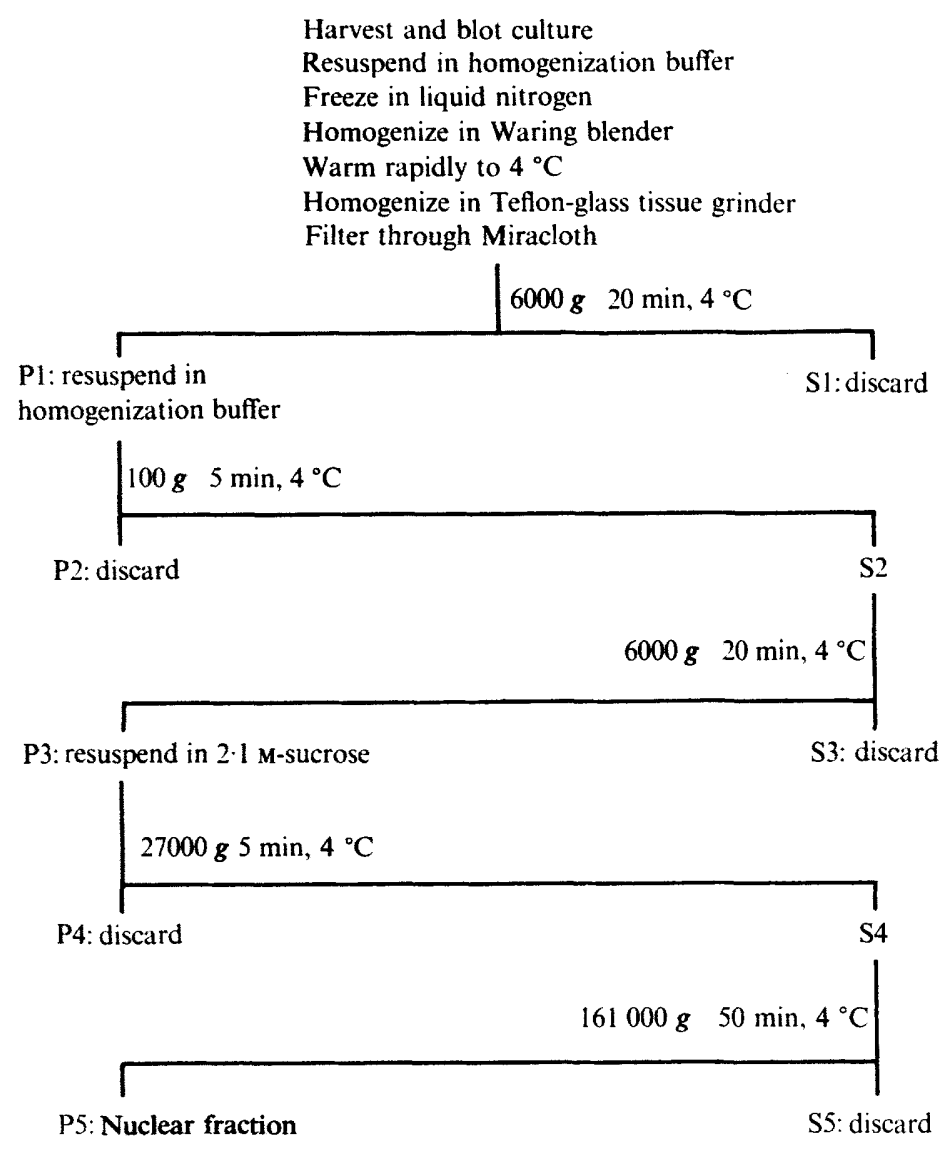

Fig. I. A schematic diagram of the procedure used to isolate nuclei from $A$, nidulans. Details are given in the Methods.

into liquid nitrogen (about 2 l). Less than 15 min was required to collect, blot dry, resuspend and freeze 60 to $120 \mathrm{~g}$ mycelium. The frozen hyphae were homogenized in a Waring blender (Model CB-5) set at highest speed; blade speed was controlled by a powerstat variable autotransformer (Superior Electric Co., Bristol, Connecticut, U.S.A., type 3PNi I68). Five $15 \mathrm{~s}$ bursts with the powerstat set at 60 to $70 \mathrm{~V}$ were used to grind $30 \mathrm{~g}$ mycelium. Approximately $250 \mathrm{ml}$ liquid nitrogen was added between grinding bursts. At the same time, the powerstat was set at $40 \mathrm{~V}$ to prevent the blade mechanism from freezing. The homogenized mycelium had the consistency of fine beach sand. By light microscopy it was estimated that 25 to $50 \%$ of the hyphae were broken. The homogenate was rapidly warmed to $4{ }^{\circ} \mathrm{C}$ by placing it in an $80^{\circ} \mathrm{C}$ water bath; all subsequent manipulations and centrifugations were done at $4{ }^{\circ} \mathrm{C}$. After adding 50 to $100 \mathrm{ml}$ of homogenization buffer, a motor-driven Teflonglass tissue grinder (Inframo motor, model RZR64; setting 5) was used to extrude nuclei sequestered within hyphae. The resulting homogenate was diluted with four volumes of homogenization buffer and filtered through Miracloth, a fresh filter being used for each $100 \mathrm{ml}$ of diluted homogenate. It was necessary to dilute the homogenate and to change the filter in order to prevent occlusion of free nuclei by the hyphal mat. The filtrate was centri- 
fuged at $6000 \mathrm{~g}$ for $20 \mathrm{~min}$ to sediment the nuclei. The resulting pellet (PI) was resuspended in approximately $150 \mathrm{ml}$ of homogenization buffer and centrifuged at $100 \mathrm{~g}$ for $5 \mathrm{~min}$ to remove any large hyphal pieces which had passed through the Miracloth. The supernatant (S2) was removed and the nuclei were again sedimented by centrifuging at $6000 \mathrm{~g}$ for $20 \mathrm{~min}$. The resulting nuclear pellet $\left(\mathrm{P}_{3}\right)$ was resuspended in the $2 \cdot \mathrm{I} \mathrm{M}$-sucrose buffer and centrifuged at $27000 \mathrm{~g}$ for $5 \mathrm{~min}$ to remove small mycelial fragments and any remaining whole cells. The resulting supernatant ( $\left.\mathrm{S}_{4}\right)$ was centrifuged at $46000 \mathrm{rev} / \mathrm{min}$ in a Spinco type 50 rotor ( $16 \mathrm{I} 000 \mathrm{~g}$ ) for $50 \mathrm{~min}$, and yielded a purified nuclear pellet (P5). Mitochondria and membranes floated to the top of the tube and formed a pellicle in this final centrifugation. The purified nuclear pellet was free of any whole cells.

\section{RESULTS AND DISCUSSION}

\section{Nuclei in situ}

The nuclei of $A$. nidulans were observed by fluorescence microscopy after fixing with modified Helly solution. When $A$. nidulans NRI was grown at $32{ }^{\circ} \mathrm{C}$, the nuclei appeared as evenly spaced, brightly stained, green ovoid bodies (Fig. $2 a$ ). Within each nucleus, the nucleolus appeared as a small red spherical region. The electron microscope revealed the nuclear structure in more detail (Fig. 2b). The diploid nucleus at interphase measured approximately $\mathrm{I} .8 \mu \mathrm{m}$ in diameter. The chromatin had both dark and light stained areas, presumably heterochromatin and euchromatin. Each nucleus was enclosed within a double membrane.

\section{Nuclear isolation}

Nuclei were isolated from 14 to $16 \mathrm{~h}$ spore-derived cultures as described in Methods. Freezing the mycelia in liquid nitrogen had two advantages: (i) it increased mycelial breakage during homogenization; and (ii) it would be expected to stop enzymic reactions instantaneously and, therefore, minimize degradation of nuclear components. Other methods of cell disruption were less successful. Homogenization of unfrozen mycelium in a Waring blender, even after incubation with snail gut enzyme, resulted in less cell breakage. Methods which caused massive cell disruption, such as the French press, also resulted in the destruction of practically all nuclei. Attempts to form protoplasts of $A$. nidulans on a scale large enough to isolate nuclei for biochemical analysis were unsuccessful. Apparently, liquid nitrogen freezing makes the cell sufficiently brittle to be sheared yet ensures sufficient protection of nuclei to prevent disruption.

The nuclear isolation procedure was monitored by fluorescence microscopy of acridine orange stained samples, which allowed us to follow the purification and determine the integrity of the nuclei. Under our conditions, the nucleus appeared as a green sphere containing a smaller red sphere; this distinct nuclear unit was readily distinguishable from all other cell constituents in the same fraction. Attempts to distinguish nuclei from other particles in the homogenate or partially-purified fractions were unsuccessful when either light or phase-contrast microscopy was used. Fluorescence microscopy also allowed us to detect nuclear disruption by looking for the separation of the red nucleolus from the rest of the nucleus and/or for leakage of the green chromatin from the nucleus. Inspection of the purified nuclear fraction showed that the chromatin was contained within the nuclear structure and that the nucleoli were still attached in approximately $70 \%$ of the nuclei (Fig. 3). Electron micrographs showed that isolated nuclei were structurally similar to the nuclei in situ (Fig. 4). A double nuclear membrane could be seen attached to the nucleus. The nuclear membrane was not complete in all nuclei and this may have been a direct result 

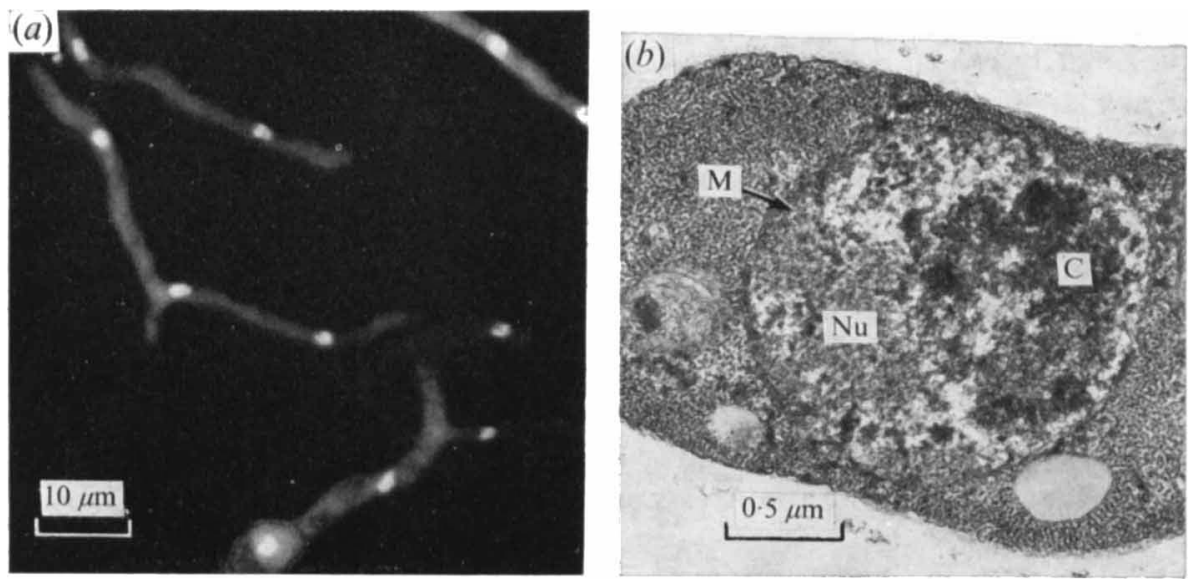

Fig. 2. In situ nuclei of $A$. nidulans NR I. (a) Fluorescence micrograph of hyphae fixed in modified Helly solution and stained with acridine orange. (b) Electron micrograph of a section through a nucleus, showing chromatin $(\mathrm{C})$, nucleolus $(\mathrm{Nu})$ and double nuclear membrane $(\mathrm{M})$.

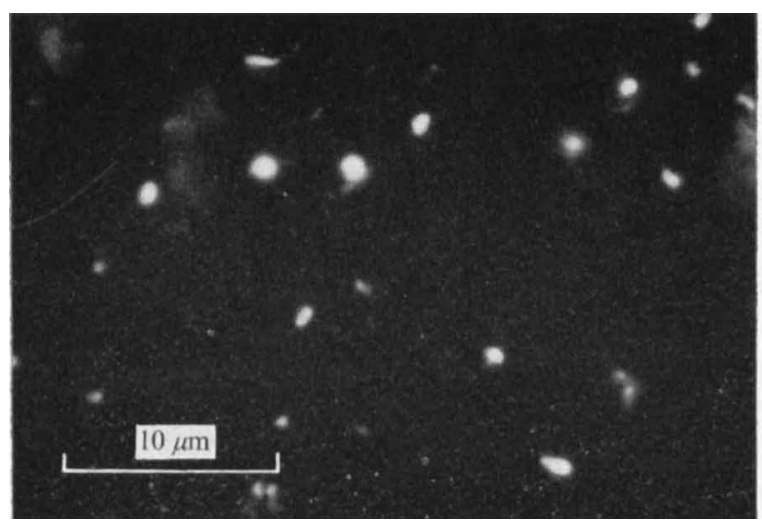

Fig. 3

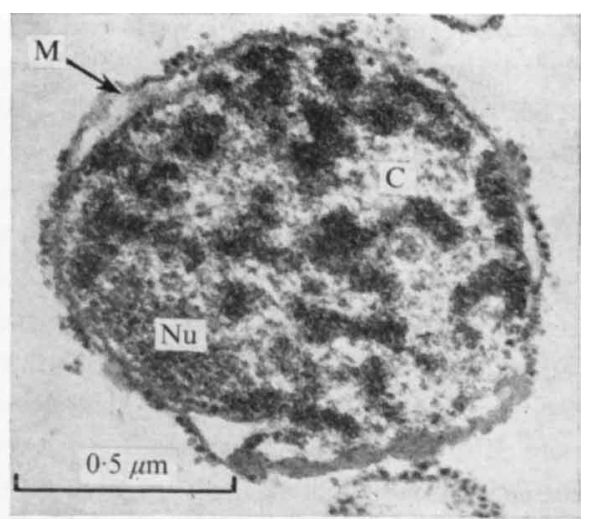

Fig. 4

Fig. 3. Isolated nuclei from $A$. nidulans NR1. Nuclei from the final purified fraction $\mathrm{P}_{5}$ (see Fig. I) were stained with acridine orange without prior fixing.

Fig. 4. An isolated nucleus from $A$. nidulans NRI. The electron micrograph shows chromatin (C), nucleolus $(\mathrm{Nu})$ and double nuclear membrane $(\mathrm{M})$.

of our procedure. Membrane connexions between the nucleus and endoplasmic reticulum have been described in other fungi (Bracker, 1967) and it is also possible that breakage of such a connexion during homogenization resulted in the rupture of the nuclear membrane. Nuclei which lacked part of their envelope were, nevertheless, not disrupted. The morphology of the chromatin and nucleolar material of the isolated nuclei were similar to the in situ nuclei. The nucleolus appeared densely packed with small, darkly-stained spheres while the chromatin showed dark and light regions, presumably heterochromatin and euchromatin, respectively. Contaminating material in the purified nuclear pellet consisted of membranebound ribosomes, plasma membrane and pieces of cell wall.

Some 15 to $20 \%$ of the cellular DNA was recovered in the purified nuclear pellet (Table I). The major loss of DNA occurred during the filtration to remove unbroken hyphae after 
Table I. Composition of Aspergillus nidulans nuclei*

\begin{tabular}{|c|c|c|c|c|c|c|}
\hline \multirow[b]{2}{*}{ Fraction } & \multirow{2}{*}{$\begin{array}{l}\text { Percentage yield } \\
\text { of DNA }\end{array}$} & \multicolumn{5}{|c|}{ Relative composition } \\
\hline & & DNA & $:$ & RNA & : & Protein \\
\hline Homogenate & 100 & I & : & $40 \cdot 8$ & : & $89 \cdot 2$ \\
\hline PI & $35 \cdot 7$ & I & : & $14 \cdot 7$ & : & $35 \cdot 2$ \\
\hline & $19 \cdot 5$ & I & $:$ & $6 \cdot 2$ & $:$ & $23 \cdot 7$ \\
\hline$P_{5}$ (nuclear fraction) & 18.8 & I & $:$ & $2 \cdot 8$ & : & $8 \cdot 7$ \\
\hline
\end{tabular}

Table 2. Composition of isolated nuclei

\begin{tabular}{|c|c|c|c|c|c|c|}
\hline & \multirow{2}{*}{$\begin{array}{l}\text { Percentage yield } \\
\text { of DNA }\end{array}$} & \multicolumn{5}{|c|}{ Relative composition } \\
\hline & & DNA & : & RNA & : & Protein \\
\hline Aspergillus nidulans & $18 \cdot 8$ & $\mathbf{I}$ & : & $2 \cdot 8$ & : & $8 \cdot 7$ \\
\hline $\begin{array}{l}\text { Saccharomyces cerevisiae } \\
\text { Doi \& Doi (1974) } \\
\text { Wintersberger } \text { et al. (1973) } \\
\text { Bhargava \& Halvorson (1971) }\end{array}$ & $\begin{array}{l}24 \\
36 \\
46 \cdot 7\end{array}$ & $\begin{array}{l}\text { I } \\
\text { I } \\
\text { I }\end{array}$ & $\begin{array}{l}\vdots \\
\vdots \\
:\end{array}$ & $\begin{array}{l}2 \cdot 7 \\
4 \cdot 2 \\
2 \cdot 5\end{array}$ & $\begin{array}{l}\vdots \\
\vdots \\
\vdots\end{array}$ & $\begin{array}{l}13 \cdot 7 \\
17 \cdot 3 \\
15.6\end{array}$ \\
\hline $\begin{array}{l}\text { Neurospora crassa (slime) } \\
\text { Hsiang \& Cole (1973) }\end{array}$ & 46 & I & : & $6 \cdot 3$ & : & ND \\
\hline $\begin{array}{l}\text { Rat (Tata, 1974) } \\
\text { Liver } \\
\text { Heart }\end{array}$ & $\begin{array}{l}70 \cdot 4 \\
43 \cdot 0\end{array}$ & $\begin{array}{l}\text { I } \\
\text { I }\end{array}$ & : & $\begin{array}{l}0.20 \\
0.26\end{array}$ & $:$ & $\begin{array}{l}3.7 \\
3.9\end{array}$ \\
\hline
\end{tabular}

ND, not determined.

homogenization. The first nuclear pellet (PI) contained only about $35 \%$ of the DNA content of the homogenate. Approximately $50 \%$ of the DNA in PI was recovered in the final nuclear fraction ( $\left.\mathrm{P}_{5}\right)$. An attempt to increase the yield of nuclei with the non-ionic detergent Triton X-I00 was not successful at concentrations of $0 . \mathrm{I}$ or $0.5 \%(\mathrm{v} / \mathrm{v})$. Fluorescence microscopy revealed that at the higher detergent concentration the nuclei appeared more disrupted, and electron microscopy showed that the nuclear membranes were removed from most nuclei. The overall recovery of DNA from $A$. nidulans was less than reported for S. cerevisiae (Bhargava \& Halvorson, 1971; Doi \& Doi, 1974; Wintersberger et al., 1973) or for the $N$. crassa slime mutant (Hsiang \& Cole, 1973). However, our recovery was better than that of Hsiang \& Cole (1973), who obtained a recovery of less than $10 \%$ from wildtype $N$. crassa using the disruption method of Reich \& Tsuda (196I). The low nuclear yield is partly compensated for by the fact that $A$. nidulans grows rapidly and that our method allows us to handle large amounts of mycelium. We are therefore able to isolate nuclei in sufficient amounts for biochemical analysis and characterization of components.

Table $\mathrm{I}$ also shows that the RNA:DNA and protein:DNA ratios decreased approximately Io-fold during purification. Since DNA, RNA and protein are all nuclear components, we cannot determine with certainty the degree of purity of the nuclei, but the Io-fold decrease in the ratios suggests at least a Io-fold nuclear enrichment. Table 2 compares the macromolecular composition of $A$. nidulans nuclei to that of nuclei from other organisms. The fungal nuclei appear to have a high content of RNA relative to DNA, compared with mammalian nuclei. This may be due to contamination with ribosomal RNA. However, $A$. nidulans has a larger nucleolus than those found in mammalian nuclei; we therefore suggest that the high nuclear RNA value may reflect the RNA content of the large nucleolus. 
The authors wish to thank Dr B. Ghosh (Rutgers Medical School) for his aid in the preparation of electron micrographs and G. Wang and M. Lai for their technical assistance. This research was supported by grants CA 10665 of the U.S. Public Health Service and GB 43404 of the National Science Foundation.

\section{REFERENCES}

Bhargava, M. M. \& Halvorson, H. O. (1971). Isolation of nuclei from yeast. Journal of Cell Biology 49, 423-429.

BRACKER, C. E. (1967). Ultrastructure of fungi. Annual Review of Phytopathology 5, 343-374.

Clutterbuck, A. J. \& Roper, J. A. (1966). A direct determination of nuclear distribution in heterokaryotes of Aspergillus nidulans. Genetical Research, Cambridge 7, I 85-194.

Dor, K. \& Dor, A. (1974). Isolation of nuclei from a tetraploid strain of Saccharomyces cerevisiae. Journal of Biochemistry 75, $1017-1026$.

Felden, R. A., SANDers, M. M. \& Morris, N. R. (1976). The presence of histones in Aspergillus nidulans. Journal of Cell Biology 68, 430-439.

GiLes, K. W. \& MYers, A. (I965). An improved diphenylamine method for the estimation of deoxyribonucleic acid. Nature, London 206, 93.

Hsiang, M. W. \& COLE, R. D. (1973). The isolation of histone sfrom Neurospora crassa. Journal of Biological Chemistry 248, 2007-2013.

Jaworski, A. J. \& Horgen, P. A. (1973). The ribosomal cistrons of the water mold Achyla bisexualis. Archives of Biochemistry and Biophysics 157, 260-267.

Lowry, O. H., Rosebrough, N. J., Farr, A. L. \& Randall, R. J. (195I). Protein measurement with the Folin phenol reagent. Journal of Biological Chemistry 193, 265-275.

Minssen, M. \& MUNKREs, K. D. (1973). Preparation of mitochondrial membrane proteins from Neurospora crassa. Prevention of lipid autoxidation by an anti-oxidant. Biochimica et biophysica acta 291, 398-410.

MoRRIS, N. R. (1976). A temperature sensitive mutant of Aspergillus nidulans reversibly blocked in nuclear division. Experimental Cell Research (in the Press).

Peberdy, J. F. \& Gibson, R. K. (1971). Regeneration of Aspergillus nidulans protoplasts. Journal of General Microbiology 69, 325-330.

Reich, E. \& TsudA, S. (1961). Isolation of nuclei from Neurospora crassa. Biochimica et biophysica acta 53, 574-575.

RoBinow, C. F. \& CATEN, C. E. (1969). Mitosis in Aspergillus nidulans. Journal of Cell Science 5, 403-43I.

Rozisn, R. H. \& Tonino, G. J. M. (1964). Studies on the yeast nucleus. I. The isolation of nuclei. Biochimica et biophysica acta 91, 105-I 12.

SARGENT, M. L. (1973). Use of liquid nitrogen and high ionic strength for the isolation of functional polyribosomes from Neurospora crassa. Biochimica et biophysica acta 324, 267-274.

SCHNEIDER, W. C. (1957). Determination of nucleic acids by pentose analysis. In Methods in Enzymology, vol. 3, pp. 680-684. Edited by S. P. Colowick and N. O. Kaplan. New York: Academic Press.

TATA, J. R. (1974). Isolation of nuclei from liver and other tissues. In Methods in Enzymology, vol. 31, pp. 253-262. Edited by S. Fleisher and L. Packer. New York: Academic Press.

Wintersberger, V., Smith, P. \& Letnansky, K. (1973). Yeast chromatin. Preparation from isolated nuclei, histone composition and transcription capacity. European Journal of Biochemistry 33, 123-130. 